Check for updates

Cite this: RSC Adv., 2017, 7, 39989

\title{
Photodegradation of sulfadiazine catalyzed by $p$ - benzoquinones and picric acid: application to charge transfer complexes $\uparrow$
}

\author{
Ahmed M. Mansour, (D) *ab Fatma A. Soliman, ${ }^{a}$ Ola R. Shehab ${ }^{a}$ and Nour T. Abdel- \\ Ghani $^{* a}$
}

\begin{abstract}
As the treatment of effluents containing the antibiotic drug sulfadiazine (SZ) is one of the challenging problems in the field of environmental chemistry, it is essential to determine the concentration of SZ by a rapid and accurate method and then find a suitable method to degrade the assayed products into harmless chemicals. The color of the charge transfer (CT) complexes developed from the reaction of SZ with 2,3-dichloro-5,6-dicyano-1,4-benzoquinone (DDQ), chloranilic acid (CHL) and picric acid (PA) was used to determine the concentration of $\mathrm{SZ}$ at 528,510 and $410 \mathrm{~nm}$, respectively. The Lambert-Beer's law is obeyed in the ranges of $6.80-68.06,13.61-136.12$ and $6.80-27.22 \mu \mathrm{g} \mathrm{mL}^{-1}$ for DDQ, CHL and PA complexes. The photolysis of SZ $\rightarrow$ DDQ in presence of sodium nitrite at $256 \mathrm{~nm}$ leads to faster degradation of SZ compared with the control experiments. This was simply spectrophotometrically followed by a decrease in the intensity of the CT band. The effect of some additives such as oxalic acid, and hematite nano particles was studied. For comparison, other $\pi$-acceptor reagents such as $\mathrm{CHL}$ and PA were used. About $80 \%$ of SZ is degraded in $45 \mathrm{~min}$ upon the illumination of SZ $\rightarrow$ DDQ at $256 \mathrm{~nm}$, whereas $90 \mathrm{~min}$ is required in the case of $\mathrm{CHL}$ and PA to attain the same degradation limit.
\end{abstract}

Received 13th May 2017

Accepted 7th August 2017

DOI: $10.1039 / c 7 r a 05433 e$

rsc.li/rsc-advances

\section{Introduction}

Sulfadiazine (4-amino- $N$-pyrimidin-2-yl-benzenesulfonamide, SZ, Scheme 1) is an effective sulfonamide drug used mainly in treatment of different types of bacterial infections. ${ }^{1}$ Sulfonamides are bacteriostatic rather than bactericidal. Their value lies in their ability to slow down or prevent bacterial multiplication in wounds or infected systems without appreciable toxicity to the body tissues. The metal complexes of SZ were found to be more effective and desirable drugs than the free drugs. $\mathrm{Zn}(\mathrm{II})-\mathrm{SZ}$ was used to prevent bacterial infection in burned animals, ${ }^{2}$ while silvadene, $\mathrm{Ag}(\mathrm{I})-\mathrm{SZ}$, was applied in the case of the topical burns. ${ }^{3}$ Several analytical methods were used for determination of SZ in the pharmaceutical formulations and biological samples such as HPLC, ${ }^{4-6}$ LC-MS,${ }^{7,8}$ fluorimetry, ${ }^{9}$ and UV-Vis. ${ }^{10-23}$

Three main reactions were reported for SZ to give colored compounds capable of absorbing light in the visible range. First, diazotization of the primary amino group and coupling

${ }^{a}$ Department of Chemistry, Faculty of Science, Cairo University, Gamma Street, Giza, Cairo 12613,Egypt.E-mail: mansour@sci.cu.edu.eg; inorganic_am@yahoo.com; noureta2002@yahoo.com; Fax:+20 2 35728843; Tel: +20 201222211253

${ }^{b}$ Institut für Anorganische Chemie, Julius-Maximilians-Universität Würzburg, Am Hubland, D-97074 Würzburg, Germany

$\dagger$ Electronic supplementary information (ESI) available. See DOI: 10.1039/c7ra05433e

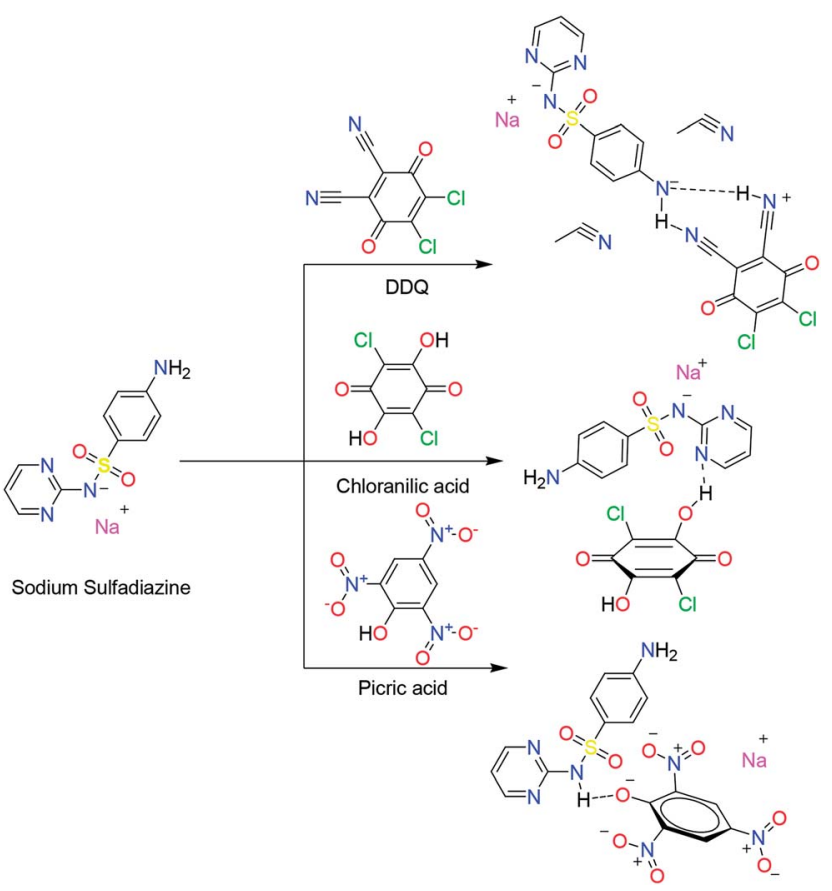

Scheme 1 Structures of SZ, and its proposed charge transfer complexes, $\mathrm{SZ} \rightarrow \mathrm{DDQ}, \mathrm{SZ} \rightarrow \mathrm{CHL}$ and $\mathrm{SZ} \rightarrow \mathrm{PA}$. 
with several reagents such as 4-amino-5-hydroxy-naphthalene-27-disulfonic acid, ${ }^{10}$ resorcinol, ${ }^{11} 3$-amino phenol, ${ }^{12}$ thymol ${ }^{13}$ and 4-naphthol ${ }^{14}$ was one of the reported methods. The coupling of SZ with $N, N$-diethyl- $p$-phenylene diamine sulfate in presence of potassium iodate gave a red color product with $\lambda_{\max }$ of $550 \mathrm{~nm} .^{15}$ Another colored compound has a $\lambda_{\max }$ of $510 \mathrm{~nm}$ was formed from the reaction of $\mathrm{SZ}$ with promethazine- $\mathrm{HCl}$ in presence of $N$-bromosuccinimide. ${ }^{16}$ Second, the $-\mathrm{NH}_{2}$ group was also used to form some Schiff-base compounds with aldehydes such as 4-dimethylaminocinnamaldehyde ${ }^{17}$ with a detection limit of $0.4-4.8 \mu \mathrm{g} \mathrm{mL}^{-1}$. The determination of SZ using some acceptors through the formation of CT complexes, was the third method. This tool was rapidly assessed for its validity as a simple quantitative analytical method. ${ }^{\mathbf{1 8 - 2 3}}$ The reported acceptors used were $p$-benzoquinone, ${ }^{18}$ tetrachlorobenzoquinone, ${ }^{19}$ tetracyano-ethylene, ${ }^{20}$ trinitro-benzene, ${ }^{21}$ safranin $\mathrm{T}^{22}$ and phenosafranine. ${ }^{23}$ The investigation of the molecular structures of some sulfonamides, including SZ, in the free acid form, with DDQ using IR, UV-Vis and ${ }^{1} \mathrm{H}$ NMR spectroscopies has been reported elsewhere. ${ }^{24}$ The authors suggested the formation of $\mathrm{H}$-bond between the $-\mathrm{NH}_{2}$ and $\mathrm{C}=\mathrm{O}$ of DDQ that did not compare well with our findings from the complete proton transfer (discussed later).

In general, the water soluble NaSZ drug might be excreted from the humans and animal without the complete metabolization and biotransformation. In addition, the expired and unused SZ may be found also in the waste water coming from the households. Therefore, the treatment of effluents containing SZ is one of the challenging problems in the field of environmental chemistry. Most of the wastewater treatment methods do not include the decomposition of the SZ residues and thus the continuous release of these fragments may be terminated with the antibiotic resistance and toxicity effects. Among the different methods used to degrade the pollutants is the photocatalytic technique ${ }^{25}$ which involves the creation of the highly reactive free radicals and safe by the formation of harmless chemicals such as water and carbon dioxide. The $\mathrm{H}_{2} \mathrm{O}_{2} / \mathrm{KI}$ assisted photo-decomposition of SZ in water at $365 \mathrm{~nm}$ was recently investigated, where the iodine radicals were proposed to be the driving force in the degradation process. ${ }^{26}$ The performance and the degradation pathways of SZ by $\mathrm{UV} / \mathrm{O}_{3}$ have been studied. ${ }^{27}$ Fenton-reagent was also used in the degradation of $\mathrm{SZ},{ }^{28,29}$ compared with $\mathrm{UV} / \mathrm{H}_{2} \mathrm{O}_{2}$ system ${ }^{28,30}$ and the relevance of the concentration and heterocyclic aromatic groups to the degradation kinetics was studied. The photochemical transformation of SZ in presence of different iron sources such as oxalate, citrate and nitrate was studied during the illumination with the sun-light. ${ }^{31}$ Unlike the Fenton tool, it was not necessary to add $\mathrm{H}_{2} \mathrm{O}_{2}$ to the degradation system, and the high degradation rate in case of the oxalate ion reflects the role of the anion in the degradation process. Immobilized $\mathrm{TiO}_{2}$ (ref. 32 and 33) and $\mathrm{TiO}_{2} / \mathrm{FeCl}_{3}$ (ref. 31, 34-36) systems were introduced as catalyst and the irradiation process was carried out at $365 \mathrm{~nm}$.

The aim of the present work is to develop a sensitive, simple, rapid and accurate spectral method for the quantitative determination of $\mathrm{SZ}$ in the pure form and the pharmaceutical preparations via the formation of CT complexes with DDQ, CHL and PA (Scheme 1). The stoichiometry, formation constant and other thermodynamic parameters were also determined. Several analytical and spectral tools were used to characterize the solid CT complex with DDQ. Geometry optimization of SZ and its complexes was done by CAM-B3LYP/6-31G(d) method. Because of the oxidative power of DDQ and its role in the oxidation of alcohols ${ }^{37}$ and oxygenation of benzene, ${ }^{38}$ for the first time, to the best of our knowledge, the photocatalytic degradation of the environmental pollutants such as the expired and unused SZ were carried out with the aid of some $\pi$ acceptor systems as well as other additives such as $\mathrm{Fe}_{2} \mathrm{O}_{3}$, oxalic acid and sodium nitrite.

\section{Experimental}

\section{Instruments}

FT IR spectra were recorded as potassium bromide pellets using a Jasco FTIR 460 plus in the range of 4000 to $200 \mathrm{~cm}^{-1} \cdot{ }^{1} \mathrm{H}$ and ${ }^{13} \mathrm{C}$ NMR spectra were run at $300 \mathrm{MHz}$ in $\mathrm{DMSO}^{-\mathrm{d}_{6}}$ using a Varian-Oxford Mercury VX-300 NMR. Elemental microanalysis was performed using ElementerVario EL III. Electronic spectra were scanned on OPTIZEN POP automate spectrophotometer.

\section{Synthesis}

One mmol of NaSz $(272 \mathrm{mg}$ ) was added to one mmol of DDQ $\left(227 \mathrm{mg}\right.$ ) in $25 \mathrm{~mL}$ acetonitrile/ $\mathrm{H}_{2} \mathrm{O}$ mixture $(100: 1)$, and then the reaction mixture was refluxed for $6 \mathrm{~h}$, whereupon the solid CT complex was precipitated. Several trials were done to prepare the solid complexes of SZ $\rightarrow$ CHL and SZ $\rightarrow$ PA, but unfortunately these trials were failed.

- Data for DDQ $\left(\mathrm{C}_{8} \mathrm{Cl}_{2} \mathrm{~N}_{2} \mathrm{O}_{2}\right) \cdot{ }^{39} \mathrm{IR}\left(\mathrm{KBr}, \mathrm{cm}^{-1}\right): 2241(\mathrm{~s}, \mathrm{C} \equiv \mathrm{N})$, 1674 (s, C=O), 1553 (s, C=C), 1450 (s, C=C), 1267 (s, C-O), 890 (m, C-Cl). UV-Vis (acetonitrile, nm): 219, 264, 286, 352 and 484.

- Data for $\mathrm{NaSZ}\left(\mathrm{C}_{10} \mathrm{H}_{9} \mathrm{~N}_{4} \mathrm{NaO}_{2} \mathrm{~S}\right)$. IR $\left(\mathrm{KBr}, \mathrm{cm}^{-1}\right)$ : 3416 $\left(\mathrm{m}, \mathrm{NH}_{2}^{\text {ass }}\right), 1630(\mathrm{~m}, \mathrm{C}=\mathrm{N}), 1292\left(\mathrm{~m}, \mathrm{SO}_{2}^{\text {ass }}\right), 1131\left(\mathrm{~m}, \mathrm{SO}_{2}^{\mathrm{ss}}\right), 977$ (w, S-N), 674 (w, C-S). ${ }^{1} \mathrm{H}-\mathrm{NMR}\left(300 \mathrm{MHz}, \mathrm{DMSO}_{6}, \delta\right): 8.06$ $\left(\mathrm{d}, 2 \mathrm{H}, \mathrm{C}-\mathrm{H}_{\text {pym }}\right) ; 6.34$ (t, $\left.1 \mathrm{H}, \mathrm{C}-\mathrm{H}_{\mathrm{pym}}\right) ; 7.48\left(\mathrm{~d}, 2 \mathrm{H}, \mathrm{C}-\mathrm{H}_{\mathrm{ph}}\right) ; 6.46$ (d, $\left.2 \mathrm{H}, \mathrm{C}-\mathrm{H}_{\mathrm{ph}}\right) ; 5.30$ (s, 2H, $\mathrm{NH}_{2}$ ).

- Data for $\mathrm{SZ} \rightarrow$ DDQ $\left(\mathrm{C}_{18} \mathrm{H}_{9} \mathrm{Cl}_{2} \mathrm{~N}_{6} \mathrm{NaO}_{4} \mathrm{~S} \cdot 2 \mathrm{CH}_{3} \mathrm{CN}\right)$ : color: dark brown. Elemental analysis (\%): calc.: C 45.45, H 2.60, N 19.27, found $\mathrm{C} 45.28, \mathrm{H} 2.44, \mathrm{~N}$ 18.38. IR $\left(\mathrm{KBr}, \mathrm{cm}^{-1}\right): 3438$ $\left(\mathrm{m}, \mathrm{NH}^{\mathrm{ass}}\right), 3223\left(\mathrm{~m}, \mathrm{NH}^{\mathrm{ss}}\right), 2211(\mathrm{w}, \mathrm{C} \equiv \mathrm{N}), 1661(\mathrm{~m}, \mathrm{C}=\mathrm{O}) .{ }^{1} \mathrm{H}-$ NMR (300 MHz, DMSO-d $\left.{ }_{6}, \delta\right): 10.96$ (s, NH), $9.94(\mathrm{~s}, \mathrm{NH}), 8.50$ (m, 2H), $8.04(\mathrm{~d}, 1 \mathrm{H}), 7.91(\mathrm{~d}, 1 \mathrm{H}), 7.62(\mathrm{~d}, 1 \mathrm{H}), 7.26(\mathrm{~d}, 1 \mathrm{H}), 7.00$ $(\mathrm{m}, 1 \mathrm{H}) .{ }^{13} \mathrm{C}-\mathrm{NMR}\left(300 \mathrm{MHz}, \mathrm{DMSO}_{6}, \delta\right): 177.26(\mathrm{C}=\mathrm{O})$, $173.13(\mathrm{C}=\mathrm{O}), 157.33,157.15,151.04,143.27,142.38,140.22$, 139.68, 136.29, 130.27, 128.64, 128.17, 127.00, 124.06, 116.27, $113.46,112.67,110.64,83.44$.

\section{Quantum chemical calculations}

Full geometry optimization of SZ, DDQ, CHL, PA and their charge transfer complexes were carried out by Gaussian 03 program package ${ }^{40}$ using density functional theory (DFT), hybrid exchange-correlation functional CAM-B3LYP with a long-range correction term ${ }^{41}$ and the split valence 6-31G(d) 
basis set. The complexes were characterized as local minima via harmonic frequency analysis.

\section{Photometric measurements}

$5 \times 10^{-3} \mathrm{~mol} \mathrm{~L}^{-1}$ stock solutions of SZ, (DDQ, CHL) and PA solutions were prepared in water, acetonitrile, and dioxane, respectively. The stoichiometry of the CT complexes in solution was determined by molar ratio ${ }^{42}$ and continuous variation ${ }^{43}$ methods. In the molar ratio method, the concentration of $\mathrm{SZ}$ was $2.5 \times 10^{-4}, 4 \times 10^{-4}$, and $1 \times 10^{-4} \mathrm{~mol} \mathrm{~L}^{-1}$ for DDQ, CHL and PA assay, respectively, while the acceptor is varied from $2.5 \times 10^{-5}$ to $4.0 \times 10^{-4}, 1.0 \times 10^{-5}$ to $6.0 \times 10^{-4}$ and $5.0 \times 10^{-5}$ to $1.5 \times 10^{-4} \mathrm{~mol} \mathrm{~L}^{-1}$ in that order. The absorbance of SZ $\rightarrow$ DDQ and SZ $\rightarrow$ CHL complexes in acetonitrile was measured at 528 and $510 \mathrm{~nm}$, while that of SZ $\rightarrow$ PA was monitored in dioxane at $410 \mathrm{~nm}$. In the continuous variation method, the same concentration $\left(5 \times 10^{-3} \mathrm{M}\right)$ of SZ and the acceptor was used. The plot of the absorbance versus the mole fraction of SZ showed a maximum at the molar ratio corresponding to the most stable formed species.

\section{Analysis of dosage form}

The analysis of SZ in Dermazin cream (30 mg, Medical Union Pharmaceutical company) was done by dissolving (500 $\mathrm{mg}$ ) the cream in a concentrated $\mathrm{H}_{2} \mathrm{SO}_{4}(10 \mathrm{~mL}, 7 \mathrm{M})$. Filtration was carried out to remove the insoluble excipients. Then, the neutralization was achieved by adding $30 \mathrm{~mL}$ of concentrated sodium hydroxide ( $5 \mathrm{M}$ ), filtration was repeated. The filtrate was treated in the same way as the standard to get the corresponding CT complexes suitable to the spectral analysis.

\section{General procedure}

Aliquots of $5 \times 10^{-3} \mathrm{~mol} \mathrm{~L}^{-1}$ of SZ solution were mixed with 0.5, 0.8 and $0.2 \mathrm{~mL}$ of DDQ, CHL and PA, respectively, in $10 \mathrm{~mL}$ volumetric flask and subsequent completed with the acetonitrile (DDQ and CHL) or dioxane (PA).

\section{Photocatalytic degradation procedure}

The photo degradation was carried out by illumination of SZ with a highly energetic UV hand lamp in presence and absence of the investigated $\pi$-acceptors. This was achieved by adding $0.5 \mathrm{~mL}$ of DDQ, $0.8 \mathrm{~mL}$ of CHL or $0.2 \mathrm{~mL}$ of PA from the stock solution $\left(5 \times 10^{-3} \mathrm{M}\right)$ to an equivalent volume of $\mathrm{SZ}$ $\left(5 \times 10^{-3} \mathrm{M}\right)$ in $10 \mathrm{~mL}$ measuring flask and then the volume was completed to the mark with acetonitrile or dioxan $(10 \mathrm{~mL})$. Then the sample was illuminated with a UV hand lamp, at two different wave lengths (256 and $365 \mathrm{~nm}$ ), positioned perpendicular at a distance of $2 \mathrm{~cm}$. The irradiation was interrupted in regular intervals to record the electronic spectrum until no further change was observed. The same experiment was repeated by addition of oxalic acid $\left(2.0 \times 10^{-4} \mathrm{M}\right)$, suspended $\mathrm{Fe}_{2} \mathrm{O}_{3}$ /oxalic acid $\left(2.0 \times 10^{-4} \mathrm{M}\right)$ and sodium nitrite $\left(1.0 \times 10^{-4}\right.$ to $\left.4.0 \times 10^{-4} \mathrm{M}\right)$.

\section{Results and discussion}

\section{Stoichiometry, stability and optimization conditions}

The reaction between SZ and the $\pi$-acceptor systems (DDQ, CHL and PA) in solution afforded CT complexes with a ratio of $1: 1$. This stoichiometry was obtained by two different methods; molar ratio and continuous variation methods (Fig. S1 \& S2 $\dagger$ ). The optimum conditions of the formation of the CT complexes and their stabilities were investigated through the study of several parameters such as the concentration of the donor and acceptors, time, $\mathrm{pH}$, and temperature. The complexes were instantaneously formed and the absorbance of the developed color remained unchanged for one hour (Fig. S3†). The optimum $\mathrm{pH}$ ranges for the complete formation and high stability of CT complexes are 5.30-12.00, 4.50-6.20 and 5.0011.20 for SZ $\rightarrow$ DDQ, SZ $\rightarrow$ CHL and SZ $\rightarrow$ PA, respectively (Fig. 1). The CT complexes are not recommended to be formed in the strongly acidic medium. A wide $\mathrm{pH}$ range was observed for both the DDQ and PA complexes formation, while it is limited for the CHL complex.

The formation constants and the molar absorptivity values of the complexes were determined by the modified Hildebrand method. ${ }^{44}$ The plot (Fig. $\mathrm{S} 4 \dagger$ ) of $\frac{C_{\mathrm{A}}^{\mathrm{o}} C_{\mathrm{D}}^{\mathrm{o}} l}{A}$ values $v s . C_{\mathrm{A}}^{\mathrm{o}}+C_{\mathrm{D}}^{\mathrm{o}}$ gives a straight line with a slope of $1 / \varepsilon$ and intercept of $\frac{1}{k \varepsilon}$, where $C_{\mathrm{A}}^{\mathrm{o}}$ and $C_{\mathrm{D}}^{\mathrm{o}}$ are the initial concentrations of the acceptor and $\mathrm{SZ}$, respectively, $A$ is the absorbance of the detected CT band and $l$ is the path-length. The values of $k_{\mathrm{f}}\left(\mathrm{L} \mathrm{mol}^{-1}\right)$ and $\varepsilon\left(\mathrm{L} \mathrm{mol}^{-1} \mathrm{~cm}^{-1}\right)$ are tabulated in Table 1 . In comparison, SZ $\rightarrow$ DDQ has higher stability than the other complexes, which was reflected in the isolation of its solid complex. This may be attributed to the proton transfer and the strong $\mathrm{H}$-bond created between the donor and the acceptor (discussed later). The oscillator strength $(f)$, which is used to measure the integrated intensity of the CT band, was calculated ${ }^{39}$ and the values are given in Table 1 . The highest $f$ value of the CT band of SZ $\rightarrow$ DDQ complex indicates a high probability of the CT transition due to the strong interaction between the donor and acceptor. The electronic donating power of SZ was measured by calculating its ionization potential

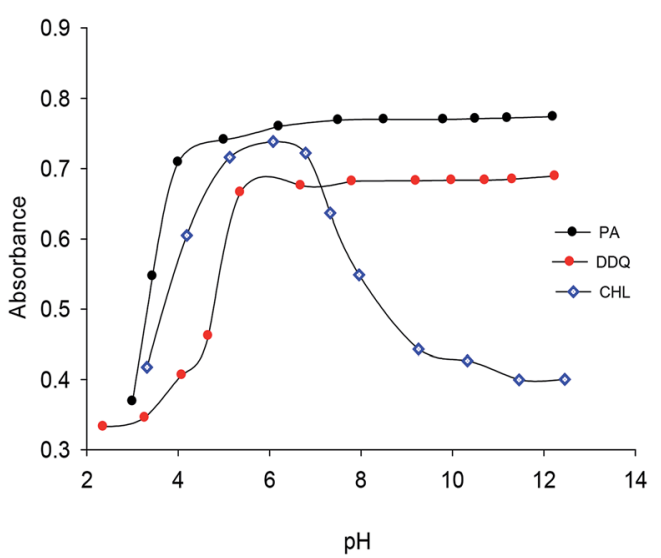

Fig. 1 Effect of pH change on the stability of the SZ charge transfer complexes. 
Table 1 Spectrophotometric data of sulfadiazine CT complexes

\begin{tabular}{|c|c|c|c|}
\hline Reagent & DDQ & Chloranilic acid & Picric acid \\
\hline$\lambda_{\max }(\mathrm{nm})$ & 528 & 510 & 410 \\
\hline$k_{\mathrm{f}}\left(\mathrm{L} \mathrm{mol}^{-1}\right)$ & $3.30 \times 10^{3}$ & $3.20 \times 10^{3}$ & $1.45 \times 10^{3}$ \\
\hline$\varepsilon\left(\mathrm{L} \mathrm{mol}^{-1} \mathrm{~cm}^{-1}\right)$ & $5.80 \times 10^{3}$ & $2.80 \times 10^{3}$ & $9.74 \times 10^{2}$ \\
\hline$I_{\mathrm{p}}(\mathrm{eV})$ & 8.66 & 8.76 & 9.49 \\
\hline$f$ & 0.0095 & 0.0056 & 0.0020 \\
\hline$\mu$ (debye) & 1.80 & 0.78 & 0.42 \\
\hline$E_{\mathrm{CT}}(\mathrm{eV})$ & 2.36 & 2.43 & 3.00 \\
\hline$\Delta G^{\mathrm{o}}\left(\mathrm{kJ} \mathrm{mol}^{-1} \mathrm{~K}^{-1}\right)$ & -14.50 & -14.34 & -12.37 \\
\hline
\end{tabular}

$\left(I_{\mathrm{p}}\right)$, which is related to the value of the wave number of the CT band $\left(I_{\mathrm{p}(\mathrm{eV})}=5.76+1.52 \times 10^{-4} \nu_{\mathrm{CT}}\right)$. The lowest $I_{\mathrm{p}}$ value of SZ in $\mathrm{SZ} \rightarrow$ DDQ suggests that SZ needs low energy to donate the electron density to DDQ molecule to form a stable complex. The standard free energy changes of complexation $\left(\Delta G^{\circ}\right)$ of the investigated complexes were calculated. As shown in Table 1, the formation of SZ $\rightarrow$ DDQ is more spontaneous and favor than the other CT complexes.

\section{Validation of Beer's law}

A subsequent of the optimization of the reaction conditions, calibration curves were constructed for SZ using the $\pi$-acceptors (Fig. S5 $\dagger$ ). It was found that Beer's law is obeyed in the concentration range of 6.80-68.06, 13.61-136.12 and 6.80$27.22 \mu \mathrm{g} \mathrm{mL}^{-1}$ for DDQ, CHL and PA. The analytical parameters of the calibration curve, Sandell's sensitivity, correlation coefficient and relative standard deviation are given in Table 2 . Therefore, PA is favored to use in the determination of low concentration of SZ, while CHL can be used for the higher concentration of SZ. The correlation coefficient values are close to the unity, which indicates that the validation of the proposed method in the applied concentration range. The intercept of the regression equation of the calibration curve is very small $((-0.045)-(0.016))$, reflecting the corroboration of Beer's law. Highest molar absorptivity value was recorded for $\mathrm{SZ} \rightarrow \operatorname{DDQ}\left(3.3 \times 10^{3} \mathrm{~L} \mathrm{~mol}^{-1} \mathrm{~cm}^{-1}\right)$ compared with the others. Detection limit is the smallest concentration of a solution of complex that can be detected with percent certainty. Based on the standard deviation of the replicate determination values under the same conditions and the slope of calibration curve, the detection limit (LOD) and the quantitation limit (LOQ) were calculated. The LOD and LOQ are found to be $0.88-7.57$ and $2.66-22.94 \mu \mathrm{g} \mathrm{mL}^{-1}$, respectively.

The selectivity of the developed method was studied by evaluating the interfering effect of some excipients used in the pharmaceutical preparations of SZ such as lactose, fructose, glucose, starch and sodium citrate. The obtained data (Table $\mathrm{S} 1 \dagger$ ) showed that the recoveries of SZ are in the range of 99.3$101.0 \%$ with no interference from these excipients. The repeatability and reproducibility of the developed method have been obtained (Table S $2 \dagger$ ) from the calculation of the intra-day and inter-day precision and accuracy by carrying out the experiment five times at three different concentrations.
Table 2 Analytical parameters of the developed spectrophotometric method

\begin{tabular}{|c|c|c|c|}
\hline Parameters & DDQ & Chloranilic acid & Picric acid \\
\hline$\lambda_{\max }(\mathrm{nm})$ & 528 & 510 & 410 \\
\hline $\begin{array}{l}\text { Linear range } \\
\left(\mu \mathrm{g} \mathrm{mL}^{-1}\right)\end{array}$ & $6.80-68.06$ & $13.61-136.12$ & $6.80-27.22$ \\
\hline $\begin{array}{l}\text { Molar absorptivity } \\
\left(\mathrm{L} \mathrm{mol}^{-1} \mathrm{~cm}^{-1}\right)\end{array}$ & $3.30 \times 10^{3}$ & $3.20 \times 10^{3}$ & $9.53 \times 10^{2}$ \\
\hline $\begin{array}{l}\text { Sandell sensitivity } \\
\left(\mu \mathrm{g} \mathrm{cm}^{-2}\right)\end{array}$ & 0.103 & 0.24 & 0.0279 \\
\hline $\begin{array}{l}\text { Relative standard } \\
\text { deviation }(\%)\end{array}$ & 1.78 & 1.67 & 1.03 \\
\hline $\begin{array}{l}\text { Detection limit } \\
\left(\mu \mathrm{g} \mathrm{mL} L^{-1}\right)\end{array}$ & 3.61 & 7.57 & 0.88 \\
\hline $\begin{array}{l}\text { Quantification limit } \\
\left(\mu \mathrm{g} \mathrm{mL}^{-1}\right)\end{array}$ & 10.95 & 22.94 & 2.66 \\
\hline Slope & 0.0096 & 0.00415 & 0.0357 \\
\hline Intercept & -0.044 & +0.016 & -0.045 \\
\hline Correlation coefficient & 0.997 & 0.996 & 0.996 \\
\hline
\end{tabular}

The ruggedness and robustness of the proposed method were assessed by another researcher and studying the influence of the small variation of the experimental variables. For example, the concentration of the acceptor was changed up and down by about $0.02 \mathrm{M}$ and the reaction time on the same manner by $2.0 \mathrm{~min}$. In these experiments, one experimental parameter was changed, while the other parameters were kept unchanged. The results (Table S3 $\dagger$ ) did not show any considerable statistical difference suggesting that the applied method is robust and rugged.

The unique properties such as the simplicity, sensitivity, repeatability and reproducibility are very important for the routine quality control analysis of SZ especially it doesn't require dull extraction, heating at high temperature and long time for the completion of the reaction. As shown in Table $\mathrm{S} 4, \dagger$ the average recoveries for the determination of SZ in Dermazin drug are in the range of 99.2-100.2\%, which reflects the high accuracy and precision of the proposed method as given by their low $\mathrm{RSD} \%$ values.

\section{Spectral characterization of solid CT complex}

To clarify the coordination sites of SZ involved in the formation of SZ $\rightarrow$ DDQ, the IR spectra of SZ and DDQ were compared with that of SZ $\rightarrow$ DDQ. The IR bands at $2241(\nu(\mathrm{C} \equiv \mathrm{N})), 1553$ $(\nu(\mathrm{C}=\mathrm{C}))$ and $890 \mathrm{~cm}^{-1}(\nu(\mathrm{C}-\mathrm{Cl}))$ are the characteristic modes ${ }^{39}$ of DDQ. The NaSZ spectrum exhibits the asymmetric mode of the $-\mathrm{NH}_{2}$ group at $3416 \mathrm{~cm}^{-1}$, while the symmetric mode is overlapped. The bands observed at 1630, 1292 and $1131 \mathrm{~cm}^{-1}$ are attributed to $\nu(\mathrm{C}=\mathrm{N})_{\mathrm{py}}, \nu\left(\mathrm{SO}_{2}^{\text {ass }}\right)$ and $\nu\left(\mathrm{SO}_{2}^{\mathrm{sS}}\right)$. In CT complex, the most noteworthy remark is the disappearance of the stretching mode of the $-\mathrm{NH}_{2}$ group and grown of two broad bands at 3438 and $3223 \mathrm{~cm}^{-1}$ because of the formation of two -NH groups. Furthermore, the $\nu(\mathrm{C} \equiv \mathrm{N})$ mode is shifted to the lower wave number, $2211 \mathrm{~cm}^{-1}$ via the proton transfer process and presence of double bond character to some extent (Scheme 1). An additional band assigned to $\nu(\mathrm{C}=\mathrm{O})$ of DDQ is observed at $1661 \mathrm{~cm}^{-1}$ in the spectrum of the CT complex. 
The ${ }^{1} \mathrm{H}$ NMR spectrum of NaSZ in DMSO displays a singlet broad signal at $\delta 5.30 \mathrm{ppm}$ with integration of two protons allocated to the $-\mathrm{NH}_{2}$ group. The aromatic protons of the pyrimidine ring give rise to one triplet and one doublet signals at $\delta 6.34$ and $8.06 \mathrm{ppm}$. The other doublet signals at $\delta 6.46$ and $7.48 \mathrm{ppm}$ are assigned to the phenyl ring. In complex, the vanishing of the $-\mathrm{NH}_{2}$ signal and appearance of two singlet signals at $\delta 9.94$ and $10.97 \mathrm{ppm}$ with the same integration value could be taken as an evidence for the proton transfer from $-\mathrm{NH}_{2}$ group to DDQ moiety. In addition, the symmetry of the aromatic signals of the phenyl ring is lost, where four doublet signals are observed at $\delta 7.26,7.62,7.91$ and $8.04 \mathrm{ppm}$. The pyrimidine ring give rises to two signals at $\delta 8.50$ and $\delta 7.00 \mathrm{ppm}$. The addition of picric acid to NaSZ was accompanied by a proton transfer, where an additional singlet signal ( $\delta 11.21 \mathrm{ppm})$ was observed.

\section{Quantum chemical calculations}

The ground state geometry optimization of the mono-negatively CT complexes was carried out at CAM-B3LYP/6-31G(d) level of theory. The geometries were characterized as local minima via the analysis of the harmonic frequencies. A view of the molecular structures, atomic numbering as well as hydrogen bond interactions between the donor and acceptor molecules is shown in Fig. 2. The bond lengths and angles are given in Tables S5-S7. $\dagger$ As shown in Fig. 2, the optimized structure of SZ $\rightarrow$ DDQ is characterized by two H-bonds, $\mathrm{N}(39) \cdots \mathrm{H}-\mathrm{N}(24)$ $\left(1.94182 \AA, 167.6^{\circ}\right)$ and $\mathrm{N}(39) \cdots \mathrm{H}-\mathrm{C}(19)\left(2.35261 \AA, 136.9^{\circ}\right)$, as a result of proton transfer from $-\mathrm{NH}_{2}$ to $\mathrm{C} \equiv \mathrm{N}$ group. An increase in the bond lengths of $\mathrm{C}(30)-\mathrm{C}(31), \mathrm{C}(36)-\mathrm{N}(39)$ and $\mathrm{C}(37)-\mathrm{N}(38)$ by $0.11723,0.01105$ and $0.06278 \AA$ is observed upon the proton transfer and $\mathrm{H}$-bond interactions. Similar, the $\mathrm{C}(19)-$ $\mathrm{C}(21)$ and $\mathrm{C}(17)-\mathrm{C}(21)$ bonds of SZ are 0.06242 and $0.05758 \AA$ lengthened upon the CT formation. Alternatively, the structure of $\mathrm{SZ} \rightarrow \mathrm{CHL}$ is stabilized by three H-bonds, which are supportive for the CT process. As the $\mathrm{H}$-bond interaction approaches more linearity as it become stronger. ${ }^{45}$ The interaction of pyrimidine $\mathrm{N}$ with the phenolic group is the strongest one with a distance of $1.57122 \AA$ and angle of $164.5^{\circ}$ compared with the other H-bonds, $\mathrm{O}(34) \cdots \mathrm{H} \cdots \mathrm{C}(2)\left(2.88785 \AA\right.$, $\left.160.1^{\circ}\right)$ and $\mathrm{Cl}(38) \cdots \mathrm{H}-\mathrm{C}(2)\left(2.98315 \AA, 132.5^{\circ}\right) .{ }^{46}$ In comparison, the $\mathrm{C}(29)-$ $\mathrm{C}(30)$ bond lengthens by $0.01084 \AA$, while the $\mathrm{C}(30)-\mathrm{O}(36)$ bond shortens by $0.02451 \AA$ as a result of the pyrimidine-phenolic interaction. The other interactions result in an increase in the bond lengths of $\mathrm{C}(31)-\mathrm{O}(34)$ and $\mathrm{C}(32)-\mathrm{Cl}(38)$ bonds by 0.00442 and $0.00616 \AA$ upon the formation of SZ $\rightarrow$ CHL complex. Five $\mathrm{H}$-bond interactions and proton transfer from the acceptor (phenolic group) to the donor (pyrimidine ring) support the stability of SZ $\rightarrow$ PA (Fig. 2). The phenyl ring participates with one nitro group in two $\mathrm{H}$-bonds with distances of $2.394(\mathrm{O}(44) \cdots$ $\mathrm{H}-\mathrm{C}(2))$ and $3.124 \AA(\mathrm{O}(34) \cdots \mathrm{H}-\mathrm{C}(1))$. Followed the proton transfer process to the pyrimidine ring, the $\mathrm{NH}$ proton is affected by two H-bonds, $1.929(\mathrm{O}(33) \cdots \mathrm{H}-\mathrm{N}(23))$ and $2.329 \AA$ $(\mathrm{O}(44) \cdots \mathrm{H}-\mathrm{N}(23))$. The last $\mathrm{H}$-bond is the strongest $\mathrm{H}$-bond interaction and is created between $\mathrm{O}(40) \mathrm{NO}$ and pyrimidine ring, $\mathrm{O}(40) \cdots \mathrm{H}-\mathrm{C}(20)$ with a distance of $2.401 \AA$ and angle $176.3^{\circ}$.

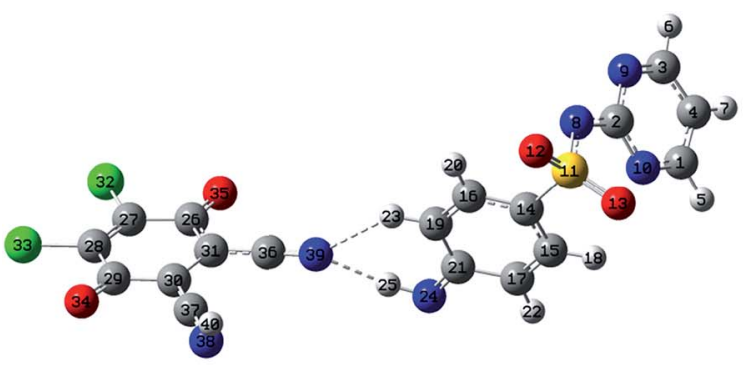

a)

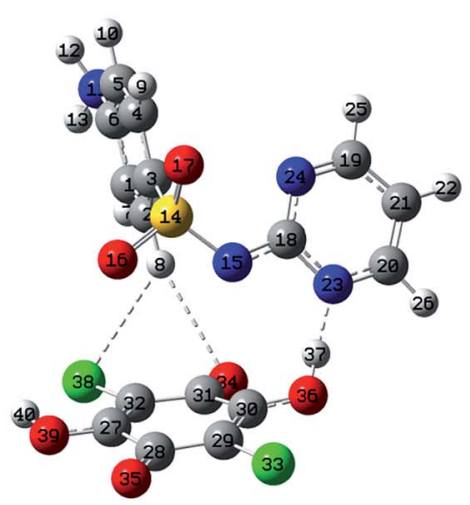

b)

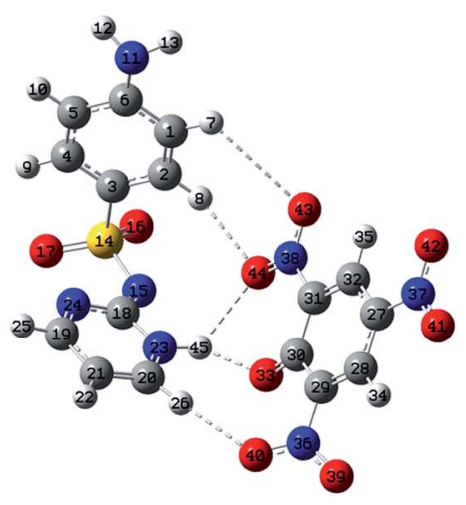

c)

Fig. 2 Local minimum structures of the mono-negatively SZ-CT complexes (a) SZ $\rightarrow \mathrm{DDQ}$, (b) $\mathrm{SZ} \rightarrow \mathrm{CHL}$, and (c) $\mathrm{SZ} \rightarrow \mathrm{PA}$, calculated by CAM-B3LYP/6-31G(d) method.

\section{Photo-catalytic degradation}

Recently, an increase consideration has been dedicated to the pharmaceutical compounds as a class of environmental pollutants. ${ }^{47,48}$ Despite the target of these compounds is to perform a biological action on human beings, may also affect other living organisms in a unexpectable way. Owing to their toxicity, sulfonamides are now replaced by other chemotherapeutics such as quinolones. ${ }^{49}$ The effectiveness of DDQ to be used as an oxidant for the oxidation of different types of the organic compounds such as alcohols ${ }^{37,38}$ encouraged us to study the photodegradation process of SZ in presence of different $\pi$ acceptor systems. As previously discussed, SZ forms stable colored complexes with some $\pi$-acceptors and it is easy to spectrophotometrically follow the degradation process. 
Illumination of the acetonitrile solution of SZ, as a control experiment at either 256 or $365 \mathrm{~nm}$ was followed by monitoring the change of the absorbance value at $239 \mathrm{~nm}$. The degradation efficiency $\left[R=100 \times\left(\left(A_{t}-A_{0}\right) / A_{0}\right)\right]$ was determined, where $A_{0}$ and $A_{t}$ are the initial absorbance and that obtained after the illumination time $(t)$. About $19.0 \%$ and $9.0 \%$ of SZ was decomposed at 256 and $365 \mathrm{~nm}$ within $3 \mathrm{~h}$ (Fig. S6†). Thus, the degradation of SZ is hardly to achieve in the absence of an oxidant. Introduction of a $\pi$-acceptor to the solution of SZ develops a colored solution. This color disappears upon the exposure to UV-light, $365 \mathrm{~nm}$. Illumination of SZ $\rightarrow$ DDQ $(2.5 \times$ $\left.10^{-4} \mathrm{M}\right), \mathrm{SZ} \rightarrow \mathrm{CHL}\left(4.0 \times 10^{-4} \mathrm{M}\right)$ and $\mathrm{SZ} \rightarrow \mathrm{PA}\left(1.0 \times 10^{-4} \mathrm{M}\right)$ systems for about $3 \mathrm{~h}$ results in degradation of about $85 \%, 49 \%$ and $8 \%$ in that order (Fig. S7†). DDQ has been shown to act as an efficient photo-oxidant.

To be able to decrease the degradation time, the combination of $\mathrm{Fe}_{2} \mathrm{O}_{3}$ nanoparticles and oxalic acid has been tested with

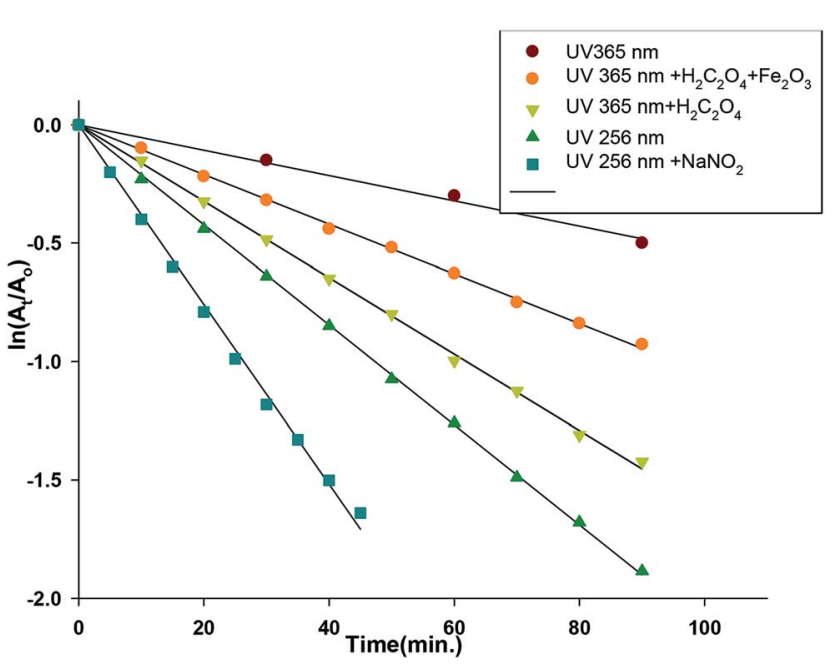

Fig. 3 Linear relationship $\ln \left(A_{t} / A_{0}\right)$ with the illumination time (min) of $\mathrm{SZ} \rightarrow \mathrm{DDQ}$ photodegradation under different conditions. the systems of CT complexes. The irradiation of the ferrioxalate complexes $^{31,34-36}$ resulted in formation of hydroxyl radicals, which may be able to accelerate the decomposition process. By using oxalic acid alone, about $77.5 \%$ and $41 \%$ of SZ were decomposed upon the illumination of SZ $\rightarrow$ DDQ and SZ $\rightarrow$ CHL systems at $365 \mathrm{~nm}$ for $90 \mathrm{~min}$, while the degradation of SZ $\rightarrow$ PA was hardly to proceed. The degradation efficiency is decreased by adding $\mathrm{Fe}_{2} \mathrm{O}_{3}$ to a system of SZ + DDQ + oxalic acid, while a highly resistance towards the degradation was observed with CHL and PA acceptors that was shown in Fig. 3. This may be attributed to complex formation and stabilization of the sulfonamide group.

High energetic UV lamp (256 nm) was used for the illumination process to increase the efficiency and rate of the degradation process. The results showed that about 78\% (SZ $\rightarrow$ $\mathrm{DDQ}), 62 \%(\mathrm{SZ} \rightarrow \mathrm{CHL})$ and $75 \%(\mathrm{SZ} \rightarrow \mathrm{PA})$ of SZ were decomposed during $90 \mathrm{~min}$. Then sodium nitrite $\left(1.0 \times 10^{-4}\right.$ to $4.0 \times 10^{-4} \mathrm{M}$ ) was tested in combination with the same light source. The decomposition rate was twofold accelerated in case of DDQ, where about $80 \%$ of SZ was degraded in $45 \mathrm{~min}$. However, the degradation percent remains nearly the same for the other two systems, as 69\% (SZ $\rightarrow$ CHL) and 76\% (SZ $\rightarrow$ PA) of SZ was decomposed in $90 \mathrm{~min}$. The photodegradation of the CT complexes was found to be a first order reaction. By plotting $\ln \left(A_{t} / A_{0}\right)$ vs. time, a linear relation was obtained with a slope corresponding to the rate constant (Table 3). Therefore, by using DDQ as an acceptor, sodium nitrite and illumination of the reaction mixture at $256 \mathrm{~nm}$, the rate and time of the degradation process are improved. The illumination process of $\mathrm{SZ} \rightarrow \mathrm{DDQ} / \mathrm{NaNO}_{2}$ system at $256 \mathrm{~nm}$ was followed by solution ${ }^{1} \mathrm{H}$ NMR studies in $\mathrm{CD}_{3}-\mathrm{CN}$ (Fig. S8 $\dagger$ ). Exclusion of $\mathrm{SO}_{2}$ gas was monitored, and detected by potassium dichromate test subsequent by formation of a variety of insoluble products, including coupling of the pyrimidine and aminobenzene rings. The broadness of the NMR signals may be taken as an indication of the creation of free radicals, which should be the motive of the degradation process.

Table 3 The rate constant, $t_{1 / 2}$ and the degradation efficiency of the degradation of SZ under different conditions

\begin{tabular}{|c|c|c|c|c|c|}
\hline Conditions $^{a}$ & Acceptor & The degradation efficiency\% & Duration time & $t_{1 / 2}(\min )$ & $k\left(\min ^{-1}\right)$ \\
\hline \multirow[t]{2}{*}{ UV light (365 nm) } & DDQ & 85 & \multirow[t]{2}{*}{180} & 126 & $5.5 \times 10^{-3}$ \\
\hline & CHL & 49 & & 177 & $3.90 \times 10^{-3}$ \\
\hline \multirow[t]{2}{*}{$\mathrm{UV} 365 \mathrm{~nm}+\mathrm{H}_{2} \mathrm{C}_{2} \mathrm{O}_{4}$} & DDQ & 77.5 & \multirow[t]{2}{*}{90.0} & 66.5 & $1.04 \times 10^{-2}$ \\
\hline & $\mathrm{CHL}$ & 41.0 & & 88.0 & $7.90 \times 10^{-3}$ \\
\hline \multirow{2}{*}{$\begin{array}{l}\text { UV } 365 \mathrm{~nm}+\mathrm{H}_{2} \mathrm{C}_{2} \mathrm{O}_{4}+\mathrm{Fe}_{2} \mathrm{O}_{3} \\
\text { UV light }(256 \mathrm{~nm})\end{array}$} & DDQ & 77.0 & \multirow{2}{*}{$\begin{array}{l}90.0 \\
90.0\end{array}$} & 48.0 & $1.60 \times 10^{-2}$ \\
\hline & PA & 75.0 & & 43.0 & $1.63 \times 10^{-2}$ \\
\hline \multirow[t]{3}{*}{$\mathrm{UV} 256 \mathrm{~nm}+\mathrm{NaNO}_{2}$} & DDQ & 80.0 & \multirow{3}{*}{$\begin{array}{l}45.0 \\
90.0\end{array}$} & 18.7 & $3.70 \times 10^{-2}$ \\
\hline & $\mathrm{CHL}$ & 69.0 & & 58.0 & $1.20 \times 10^{-2}$ \\
\hline & PA & 76.0 & & 47.0 & $1.03 \times 10^{-2}$ \\
\hline
\end{tabular}

${ }^{a} 0.5 \mathrm{~mL}$ of DDQ, $0.8 \mathrm{~mL}$ of CHL or $0.2 \mathrm{~mL}$ of PA from the stock solution $\left(5 \times 10^{-3} \mathrm{M}\right)$ was mixed with the equivalent volume of SZ (5 $\left.\times 10^{-3} \mathrm{M}\right)$ in $10 \mathrm{~mL}$ measuring flask and then the volume was completed to $10 \mathrm{~mL}$. The same experiment was repeated by addition of oxalic acid $\left(2.0 \times 10^{-4} \mathrm{M}\right)$, suspended $\mathrm{Fe}_{2} \mathrm{O}_{3} /$ oxalic acid $\left(2.0 \times 10^{-4} \mathrm{M}\right)$ and sodium nitrite $\left(1.0 \times 10^{-4}\right.$ to $\left.4.0 \times 10^{-4} \mathrm{M}\right)$. 


\section{Conclusion}

The determination of sulfadiazine has been spectrophotometrically performed through the formation of three charge transfer complexes with 2,3-dichloro-5,6-dicyano-1,4-benzoquinone (DDQ), chloranilic acid (CHL) and picric acid (PA). The Lambert-Beer's law was obeyed in the ranges of 6.80-68.06, 13.61-136.12 and 6.80-27.22 $\mu \mathrm{g} \mathrm{mL}^{-1}$ for DDQ, CHL and PA complexes. The CT complexes are not recommended to be formed in the strongly acidic medium. DDQ and PA are favored to use in the determination of the low concentration of SZ, while CHL can be used for the high concentration of SZ. The results did not show any considerable statistical difference suggesting that the applied method is robust and rugged. The IR and NMR data of SZ $\rightarrow$ DDQ revealed charge transfer process accompanied by proton transfer from $-\mathrm{NH}_{2}$ of $\mathrm{SZ}$ to $\mathrm{C} \equiv \mathrm{N}$ of DDQ. Density functional theory calculations indicated that the stabilization of the CT complexes is attributed to presence of several $\mathrm{H}$-bond interactions. Owing to the oxidative power of DDQ, for the first time the $\pi$-acceptors were investigated in the photodegradation process of the investigated drug. The degradation of SZ is hardly to achieve in the absence of an oxidant or in presence of iron(III) oxide. Illumination of SZ $\rightarrow$ DDQ system at $365 \mathrm{~nm}$ for about $3 \mathrm{~h}$ resulted in degradation of about $85 \%$. By using $256 \mathrm{~nm}$ as a light source, the time was decreased to $90 \mathrm{~min}$. The decomposition rate was twofold accelerated at $256 \mathrm{~nm}$ by adding sodium nitrite to the reaction mixture.

\section{Conflicts of interest}

There are no conflicts to declare.

\section{Acknowledgements}

Ahmed M. Mansour thanks the Alexander von Humboldt foundation for a postdoctoral fellowship.

\section{References}

1 A. M. Romero, C. G. Benito and J. M. Calatayud, Anal. Chim. Acta, 1995, 308, 451-456.

2 (a) N. C. Baenziger, S. L. Modak and C. L. Fox, Acta Crystallogr., Sect. C, 1983, 39, 1620; (b) C. J. Brown, D. S. Cook and L. Sengier, Acta Crystallogr., Sect. C, 1985, 41, 718.

3 (a) N. C. Baenziger and A. W. Struss, Inorg. Chem., 1976, 15, 1807; (b) D. S. Cook and M. F. Turner, J. Chem. Soc., Perkin Trans. 2, 1975, 1021.

4 A. V. Herrera, J. Hernandez-Borges, T. M. Borges-Miquel and M. A. Rodríguez-Delgado, J. Pharm. Biomed. Anal., 2013, 75, 130.

5 C. Lin and S. Huang, Anal. Chim. Acta, 2008, 612(1), 37.

6 K. E. Maudens, G. Zhang and W. E. Lambert, J. Chromatogr. A, 2004, 1047(1), 85.

7 S. De-Baere, K. Baert, S. Croubels, P. De-Backer, J. De-Busser and K. De-Wasch, Analyst, 2000, 125(3), 409.

8 T. A. M. Msagati and M. M. Mathew, Talanta, 2004, 64(1), 87.
9 R. Diez and M. C. O. Sarabia, Anal. Chim. Acta, 2007, 585(2), 350.

10 N. D. Dinesh, P. Nagaraja and K. S. Rangappa, Proc. Natl. Acad. Sci., India, Sect. A, 2002, 72(3), 231.

11 P. Nagaraja, K. R. Sunitha, R. A. Vasantha and H. S. Yathirajan, Indian J. Pharm. Sci., 2002, 64(4), 391.

12 P. Nagaraja, H. S. Yathirajan, C. R. Raju, R. A. Vasantha, P. Nagendra and M. S. Hemantha-Kumar, Farmaco, 2003, 58(12), 1295.

13 S. A. Dhahir and A. H. Mhemeed, Asian J. Chem., 2012, 24(7), 3053.

14 P. Nagaraja, H. R. Arun-Kumar, S. D. Naik, A. K. Shrestha and A. Shivakumar, Indian Pharm., 2007, 6(64), 76.

15 P. Nagaraja, A. K. Shrestha, A. Shivakumar and A. K. Gowda, Acta Pharm., 2010, 60(2), 217.

16 N. D. Dinesh, P. Nagaraja and K. S. Rangappa, J. Indian Chem. Soc., 2003, 80(10), 934.

17 S. Raghuveer, I. R. K. Raju, D. K. Vatsa and C. M. R. Srivastava, Indian Drugs, 1993, 30(4), 191.

18 A. I. Mohamed, H. F. Askal and G. A. Saleh, J. Pharm. Biomed. Anal., 1991, 9(7), 531.

19 X. Zhou, L. Feng, W. Zhou, G. Zhao, J. Yang and N. Zhang, Fenxi Huaxue, 1999, 27(2), 244.

20 A. M. Nour El-Din, Arch. Pharm., 1986, 319(2), 143.

21 Y. M. Issa, H. B. Hassib, A. L. El-Ansary and S. Z. Henein, ACH - Models Chem., 1994, 131(5), 607.

22 A. S. Al-Attas, J. Saudi Chem. Soc., 2002, 6(2), 201.

23 A. S. Al-Attas, Saudi Pharm. J., 2003, 11(3), 141.

24 A. L. El-Ansary, H. B. Hassib, Y. M. Issa and S. Z. Henein, Egypt J. Chem., 1997, 40(3), 201.

25 (a) A. M. Mansour, RSC Adv., 2015, 5, 62052; (b) A. M. Mansour, E. M. El-Bakry and N. T. Abdel-Ghani, J. Photochem. Photobiol. A. Chem., 2016, 327, 21.

26 H. Wei, X. Yang, K. Li and T. Min, Huanjing Kexue Xuebao, 2016, 36(5), 1697.

27 W. Guo, Z. Yang, J. Du, R. Yin, X. Zhou, S. Jin and N. Ren, RSC Adv., 2016, 6, 57138.

28 A. P. S. Batista, F. C. C. Pires and A. C. S. C. Teixeira, J. Photochem. Photobiol. A. Chem., 2014, 286, 40.

29 A. P. S. Batista and R. F. P. Nogueira, J. Photochem. Photobiol. A. Chem., 2012, 232, 8.

30 N. Lemanska-Malinowska, E. Felis and J. Surmacz-Gorska, Arch. Environ. Prot., 2013, 39(3), 79.

31 A. P. S. Batista, B. A. Cottrell and R. F. P. Nogueira, J. Photochem. Photobiol. A. Chem., 2014, 274, 50.

32 J. Zhang, M. Xia, H. Wei, G. Wang and R. Han, Anquan Yu Huanjing Xuebao, 2014, 14(6), 143.

33 W. Baran, J. Sochacka and W. Wardas, Chemosphere, 2006, 65(8), 1295.

34 E. Adamek, W. Baran, J. Ziemianska and A. Sobczak, Appl. Catal., B, 2012, 126, 29.

35 J. Zhang, D. Fu, L. Yang, L. Deng and Y. Sun, J. Southeast Univ., 2011, 27(3), 275.

36 W. Baran, E. Adamek, A. Sobczak and A. Makowski, Appl. Catal., B, 2009, 90(3-4), 516.

37 L. Wang, J. Li, H. Yang, Y. Lv and S. Gao, J. Org. Chem., 2012, 77,790 . 
38 K. Ohkubo, A. Fujimoto and S. Fukuzumi, J. Am. Chem. Soc., 2013, 135, 5368.

39 O. R. Shehab and A. M. Mansour, J. Mol. Struct., 2015, 1093, 186.

40 M. J. Frisch, G. W. Trucks, H. B. Schlegel, G. E. Scuseria, M. A. Robb, J. R. Cheeseman, V. G. Zakrzewski, J. A. Montgomery, R. E. Stratmann, J. C. Burant, S. Dapprich, J. M. Millam, A. D. Daniels, K. N. Kudin, M. C. Strain, O. Farkas, J. Tomasi, V. Barone, M. Cossi, R. Cammi, B. Mennucci, C. Pomelli, C. Adamo, S. Clifford, J. Ochterski, G. A. Petersson, P. Y. Ayala, Q. Cui, K. Morokuma, D. K. Malick, A. D. Rabuck, K. Raghavachari, J. B. Foresman, J. Cioslowski, J. V. Ortiz, A. G. Baboul, B. B. Stefanov, G. Liu, A. Liashenko, P. Piskorz, I. Komaromi, R. Gomperts, R. L. Martin, D. J. Fox, T. Keith, M. A. Al-Laham, C. Y. Peng, A. Nanayakkara, C. Gonzalez, M. Challacombe, P. M. W. Gill, B. G. Johnson, W. Chen, M. W. Wong, J. L. Andres, M. Head-Gordon, E. S. Replogle and
J. A. Pople, GAUSSIAN 03 (Revision A.9), Gaussian, Inc., Pittsburgh, 2003.

41 T. Yanai, D. Tew and N. Handy, Chem. Phys. Lett., 2004, 393, 51-57.

42 J. H. Yoe and A. L. Jones, Ind. Eng. Chem., Anal. Ed., 1944, 16, 14.

43 W. C. Vosburgh and G. R. Cooper, J. Am. Chem. Soc., 1941, 63, 437.

44 H. A. Benesi and J. H. Hildebrand, J. Am. Chem. Soc., 1949, 71, 2703.

45 A. M. Mansour, Dalton Trans., 2015, 43, 15950.

46 P. Malla, D. Marion, E. V. Ivanova and H. M. Muchall, J. Mol. Struct., 2010, 979, 101.

47 D. Kolpin, E. Furlong, M. Meyer, E. Thurman, S. Zaugg, L. Barber and H. Buxton, Environ. Sci. Technol., 2002, 36, 1202.

48 M. L. Richardson and J. M. Bowron, J. Pharm. Pharmacol., 1985, 37, 1.

49 A. M. Mansour, Inorg. Chim. Acta, 2013, 394, 436. 